\title{
Surge Analysis Using Transient Pressure Theory
}

\author{
S.S.Valunjkar \\ Government College of Engineering, Karad, Shivaji University, Kolhapur, Maharashtra, INDIA.
}

\begin{abstract}
Propagation Transient waves results due to time dependent flow with rapid change of controlling parameters. Penstock of hydel turbines or closed conduits/ pipes carrying water may observe transient wave propagation, introducing the Joukowsky pressure rise, following instantaneous flow stoppage. The dependence of transient propagation velocity on the pipe and fluid properties as well as free gas content is dealt in this paper. A mathematical model based on equations of continuity and momentum applied to general element of fluid is developed in terms of differential equations pertaining to surge analysis, surface wave propagation and low amplitude air pressure transient analysis. Effect of column separation and trapped air in the surge analysis is discussed as an outcome of simulation model.
\end{abstract}

Keywords; Surge, column separation, and transient pressure

\section{INTRODUCTION}

Installations having large capacity involve incompressible fluid flow (i.e. when mass density $\rho$ is constant), surge is complex phenomenon, which governs design, operation and maintenance of the system. The surge analysis based on classical treatment of water hammer, addressing pressure oscillations causing flow cessation due to Joukowsky pressure rise. This situation arises due instantaneous flow stoppage. In water supply system end conditions may be: (i) Constant pressure reservoir; (ii) Dead end; and (iii) Trapped air. As the valve is closed, fluid approaching its upstream face is retarded, consequent upon compression of the fluid and expansion of pipe cross section. Pressure rise at valve results in a pressure wave being propagated upstream, which conveys the retardation of flow to the column of fluid approaching the valve along the upstream pipeline. This pressure wave travels through the fluid at sonic velocity, which will be dependent on properties of fluid and pipe dimensions and material. Similarly, on the downstream side of the valve the retardation of flow results in reduction in pressure at the valve, with the result that a negative pressure wave is propagated along the downstream pipe which, in turn, retards the fluid flow.

However, assumption that downstream sides pressure drop is insufficient to reduce fluid pressure up to vapour pressure or dissolved gas release pressure. Thus, closure of valve results in propagation of pressure waves along upstream and downstream sides of the pipe, although these waves are of different sign relative to steady pressure in the pipe prior to the valve operation. Hence the effect is to retard the flow in both pipe sections. The upstream pipe swells as the pressure rise wave passes along it, while downstream pipe contracts owing to the passage of the pressure-reducing wave. The magnitude of the deformation of pipe depends upon pipe material. At the closure of valve pressure-time history of the system will depend on the boundary conditions. Pressure wave from the valve reaches in $t=L / c$ to layer of the fluid at interface of reservoir and pipe. It is impossible for the layer of the fluid adjacent to the reservoir inlet to maintain a pressure, different from prevailing at that depth in the reservoir. Hence a restoring pressure wave having magnitude sufficient to bring the pipe line pressure back to its value, prior to valve closure is transmitted from each reservoir at time $t=L / c$. For upstream pipe pressure wave is propagated towards close valve, restoring the pipe cross section and reducing pipe pressure to its initial value. This wave propagation will also cause fluid flow from pipe into the reservoir as the pipe ahead of moving wave is at a higher pressure than the reservoir. At downstream reservoir, the converse occurs, resulting in the propagation of a pressure rise wave towards the valve and the establishment of flow from the downstream flow towards the valve. Hence the restoring pressure wave in both pipes reaches the valve at a time $t=2 L / c$.

\section{Model For Wave Propagation}

The propagation of pressure transient in closed conduit/pipe flow, or surface waves in free surface unsteady flow, may be defined by applying unsteady state equations of motion and continuity. The dependent variables are the fluid's average velocity and pressure, or depth, at any flow cross section. The independent variables are time and distance, assumed positive in the initial steady flow direction and therefore the defining equations are set of partial differential equations. The main assumptions are made in the derivation of the equations are: 


\section{i. The flow in the conduit/ pipe is one dimensional}

ii. Conditions are assumed to change sufficiently slowly that the frictional losses to be incorporated in the momentum equation may be based on values derived from steady flow relationships. Friction will also be assumed to be proportional to square of the velocity.

iii. Where appropriate the conduit / pipe wall and the fluid are linearly elastic. This is true for most fluids and conduit materials e.g. metal, concrete, rock tunnels.

iv. For full-bore flows the conduit/ pipe remains full of fluid at a pressure exceeding the vapour pressure of the fluid or gas release pressure.

\section{Equation of Motion}

The equation of motion may be derived by considering free body diagram of elementary area of fluid within the conduit comprising of two opposing pressure forces, a component of pressure force due to the change in element cross section area and a gravity force based on element's fluid mass. It is equal to product of fluid element mass and acceleration. The equation may be expressed in terms of velocity and pressure as:

$V \frac{\partial V}{\partial x}+\frac{\partial V}{\partial t}+\frac{1}{\rho} \frac{\partial p}{\partial t}-g \sin \alpha+\frac{f V|V|}{2 m}=0$

where, $\mathrm{V}=$ Velocity of fluid, $\rho=$ density of fluid, $\mathrm{p}=$ pressure of fluid, $\alpha=$ angle of conduit/pipe, $|\mathrm{V}|=$ modulus of velocity and $\mathrm{m}=$ flow hydraulic mean depth.

Equation of Continuity

It is derived from law of conservation of mass for an element of fluid flowing in the conduit Parmakian J. [1]. The equation is:

$\frac{\partial V}{\partial x}+\frac{1}{\rho} \frac{\partial p}{\partial x}+\frac{1}{A} \frac{d A}{d t}=0$

where, $\frac{\partial V}{\partial x}$ accounts for change between inflow, outflow $\frac{1}{\rho} \frac{\partial p}{\partial x}=$ accounts for liquid compressibility;

and $\frac{1}{A} \frac{d A}{d t}=$ accounts for the radial change in and outflow conduit /pipe size. The bulk modulus of elasticity $\mathrm{K}$ of fluid may be defined as $K=\rho\left(\frac{d p}{d \rho}\right)$ leads to continuity equation in the form:

$\left[\frac{1}{K}+\frac{D}{E e}\right] \frac{d p}{d x}+\frac{\partial V}{\partial x}=0$

where, $\mathrm{D}=$ pipe diameter, $\mathrm{e}=$ pipe wall thickness and $\mathrm{E}=$ Young's modulus of pipe material. It may be written as:

$\frac{1}{\mathrm{c}^{2}}=\rho\left[\frac{1}{\mathrm{~K}}+\frac{\mathrm{D}}{\mathrm{Ee}}\right]$

where $\mathrm{c}=$ wave propagation /celerity in $\mathrm{m} / \mathrm{s}$. This value can be compared with the expression for sonic velocity in an infinite expanse of the fluid given by $\left(\frac{K}{\rho}\right) 0.5$. Pipe-fluid equivalent bulk modulus $\mathrm{K}^{\prime}$ expressed as:

$\frac{1}{\mathrm{~K}^{\prime}}=\frac{1}{\mathrm{~K}}+\frac{\mathrm{D}}{\mathrm{Ee}}$ and wave speed in the fluid pipe system is given as:

$\mathrm{c}^{2}=\frac{\mathrm{K}^{\prime}}{\rho}=\frac{1}{\rho}\left[\frac{\mathrm{K}}{1+\frac{\mathrm{DK}}{\mathrm{Ee}}}\right]$

The continuity equation finally written as:

$\frac{\partial \rho}{\partial \mathrm{t}}+\mathrm{V} \frac{\partial \mathrm{p}}{\partial \mathrm{x}}+\rho \mathrm{c}^{2} \frac{\partial \mathrm{V}}{\partial \mathrm{x}}$

Considering $\mathrm{E}$ is not negligible than $\mathrm{K}$, thus longitudinal strain has been neglected in the above derivation.

\section{COLUMN SEPARATION AND TRAPPED AIR BOUNDARY CONDITIONS}

In the reservoir system it was observed that, following valve closure, the negative reflections from the upstream tank could reduce the pressure at the valve face to the fluid vapour pressure ; Fox J. A. [2]. Let $\mathrm{N}=$ number of pipe sections. If this occurs and a simple check on calculated pressure values at the [N+1] section will confirm this, then the fluid column breaks away from the valve and moves towards the reservoir, continuing to travel in this direction until brought to rest by the adverse pressure gradient between the tank pressure pair1 and the vapour pressure at the valve face. The same pressure gradient accelerates the flow back towards the closed valve, closing the cavity and generating a large pressure rise when the column is brought to rest by the 
closed valve. The boundary condition $\left[\bar{u}_{N}+1\right]=0$ applied at the valve following closure obviously breaks down during the pressure of the cavity and is replaced by the pressure boundary equation.

Equations

$[p N+1]=$ vapour pressure $=\rho_{\text {vap }}$

Solving this with $\mathrm{C}+$ characteristics yields

$\left[\bar{u}_{N}+1\right]=K_{1}-K_{2} p_{v a p}$

From following equation:

$V_{p}=V_{R}-\frac{1}{P C_{R}}\left(p_{p}-p_{R}\right)+g \sin \alpha R \Delta t-\frac{4 f_{R} V_{R}\left|V_{R}\right| \Delta t}{P C_{R} 2 D_{R}}$

$\frac{d x}{d t}=V+c$, and

$V_{p}=V_{s} \frac{1}{\rho C_{s}}\left(p_{P}-p_{s}\right)+g \sin \alpha_{s} \Delta t-\frac{4 f_{s} V_{s}}{\rho C_{s}} \frac{\left|V_{s}\right| \Delta t}{2 D_{s}}$

When

$\frac{d x}{d t}=V-c$ the equation (1)and $\frac{d x}{d t}=V \pm c, \Delta \mathrm{t} \leq \Delta \mathrm{x} / V+c$, known as Courant stability criteria are the characteristic equations and, as a pair of total derivative equations are solved using finite difference techniques. The equation (1) relates the known conditions at $\mathrm{R}$ and $\mathrm{S}$ in an $\mathrm{x}-\mathrm{t}$ plane (Figure 1) to unknown conditions at $\mathrm{P}$. In order to determine, duration of application of the pressure boundary condition, the volume of the cavity $\mathrm{V}$ calculated on time step basis as:

$V_{t+\Delta t}=V_{t}-\left(\frac{A}{2}\right) \Delta t\left(\left[\bar{u}_{N}+1\right]+\bar{u}_{N}+1\right)$

where the term in square bracket represents the velocity at time $t+\Delta t$, so that the mean velocity over the time step is used in cavity volume submission, and $\mathrm{A}$ is pipe cross sectional area. If the value of $\mathrm{V}$ is monitored, the collapse of cavity is indicated by $V=0$. The negative sign in equation (10) is included so that the cavity volume increases in positive manner for reverse flow in the pipe. The pressure rise on cavity collapse may be more severe than the pressure rise on valve closure. Considering slow valve closure, taking several pipe periods; then the pressure rise is considerably less than the one pipe period closure rise of $\rho c \overline{0} 0$. However, the pressure rise on cavity collapse is the equivalent of instantaneously stopping a flow at a velocity $\bar{u}$, where ûf is the final column velocity as it accelerates towards the closed valve; the resultant pressure rise is being $\rho$ cuf. This illustrates the importance of testing for the possibility of column separation; Wylie E. B. and Streeter V.L.[3].

\section{TRAPPED AIR AT A DEAD END OR ClOSED VAlVE}

The air pocket may be treated as terminal boundary condition for the branch; Douglas J.F. et al [4]. This boundary arises as a result of flow condition within the network and hence it is included in a model as boundary activated by the predicted flow conditions during transient propagation. In the Figure 1 the volume of gas is assumed known at some base pressure conveniently atmospheric, although the network steady flow pressure would also be suitable. The unknowns are the fluid velocity at the fluid/gas interfaceand the pressure in the free gas volume. The volume of gas is assumed small compared with the pipe volume represented by one computing section $\Delta \mathrm{x}$. The available equations are the $\mathrm{C}+$ characteristic at pipe exit, equation (9) and the gas law expressed as:

$\left(P_{\text {gas }}\right)^{t+\Delta t}\left[\left(\text { Vol }_{\text {gas }}\right)^{t+\Delta t}\right]^{n}=\left(P_{\text {gas }}\right)^{t 0}\left[\left(\text { Vol }_{\text {gas }}\right)^{t 0}\right]^{n}$

where $1<\mathrm{n}<1.4$

The volume of gas may be calculated at each time step from the summation.

$\left(V_{o l} l_{\text {gas }}\right)^{t+\Delta t}=\left(V_{o l} l_{\text {gas }}\right)^{t}-0.5(J) \Delta t\left[V_{P}\left(J, n(J)+1+V_{P}(J, n(J)+1)\right]\right.$

where $V_{P}(J, n(J)+1)$ is the interface velocity at time t, i.e. one time step earlier, an approach identical to column separation cavity summation. The minus sign in the gas volume summation ensures that the gas pocket volume decreases if the flow in the branch pipe is positive, i. e. towards the dead end.

In the cases where there is air leakage from the dead ended pipe, as per Figure 1, the gas pressure rises. The leakage of gas, $\mathrm{q}$, from the pipe will depend on the equivalent orifice equation given as:

$\left(P_{\text {gas }}\right)^{\text {time }}-P_{\text {external }}=K_{\text {orifice }}\left[\left(q_{\text {gas }}\right)^{\text {time }}\right]^{2}$

And therefore, 

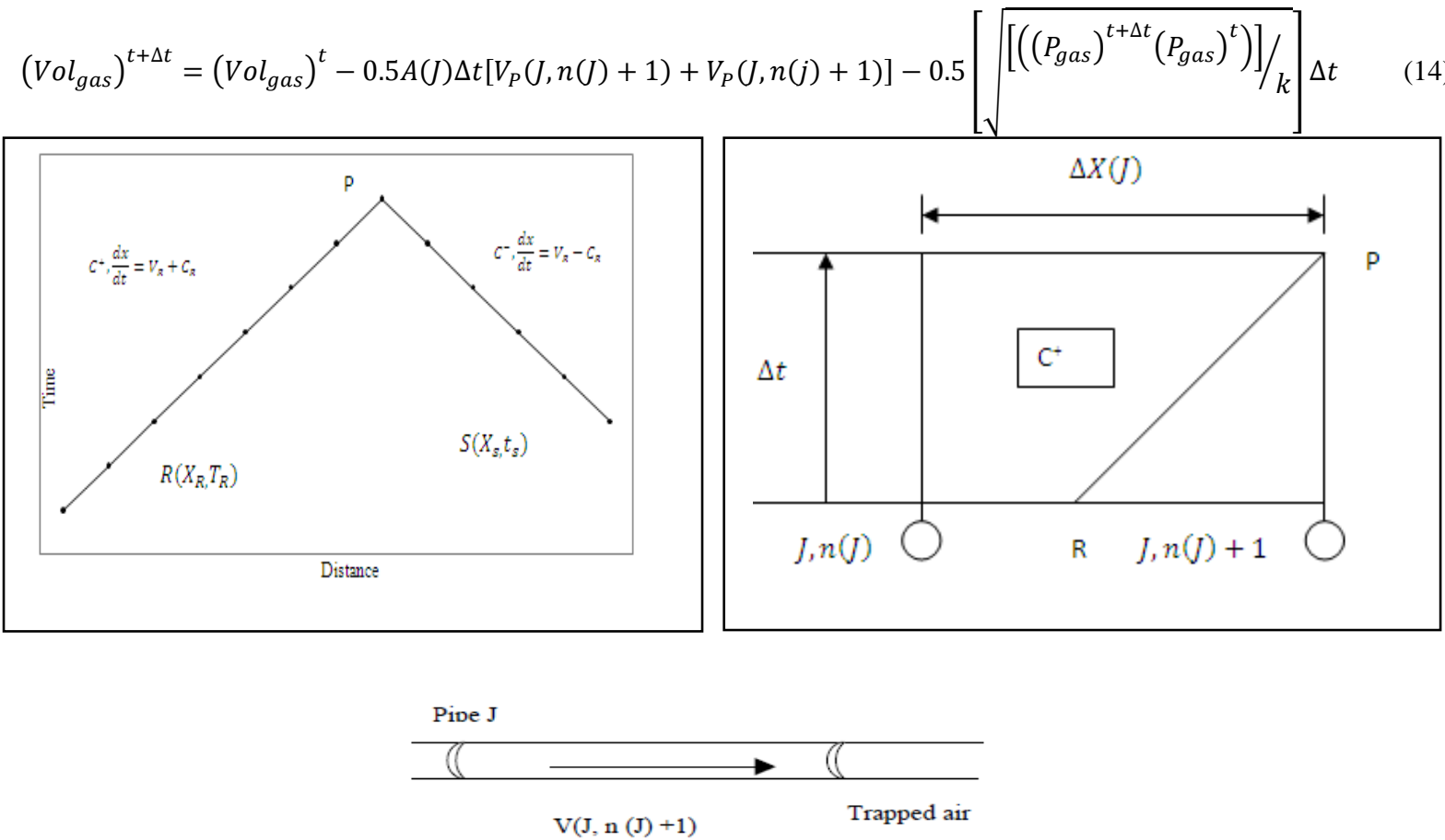

Figure 1 First order approximation of $\mathrm{C}$ higher and lower values in $\mathrm{x}$-t plane

\section{ALGORITHM}

The software developed with aid of Schildt H [5]; in the present study, calculates the pressure transient propagation in a pipeline linking two pressure-controlled tanks. Fluid flows between the tanks by differential pressure and transients are propagated as a result of valve operation [6]. Wave propagation speed was calculated from input data describing the fluid and the conduit/pipe.

\section{Surge Analysis}

Input data

1.Pipe data: length (L), diameter (D), wall thickness (T), Young's modulus (E), friction factor (f) and vapour pressure ( Pvap)in SI units;

- Discharge or flow $(Q o)$ rate in $\mathrm{m}^{3} / \mathrm{s}$;

- fluid data: density $(\rho)$ and bulk modulus $(K)$ in SI units;

- $c=\sqrt{K /(\rho(1.0+(D * K))) /(E * T)}$

- Number of pipe sections $(\mathrm{N})$;

$\mathrm{DX}=\mathrm{L} / \mathrm{N}$

$\mathrm{DT}=\mathrm{DX} / \mathrm{c}$

Vol_1 $=0.0$

Vol_2 $=0.0$

- Valve position at upstream entry or exit, Valve characteristic

- For ILOV=1; 'UPSTREAM VALVE' For ILOV=2; 'DOWNSTREAM VALVE'

- 'Valve characteristics' in terms of single pressure loss (Dpo) in terms of flow rate (Qvo) in m3/s;

- Duration (Tc) and direction of valve motion (VDIR)

For VDIR = 0; 'VALVE CLOSED' in Tc seconds. For VDIR = 1 'VALVE OPENED' in Tc seconds.

- Overall simulation time in seconds (Tmax);

- Upstream reservoir pressure (PR1)

For ILOV=2 and VDIR=1; 'Down stream reservoir pressure' (PX) 
- Input line pressures (Line_Pr) less than upstream reservoir pressure; if entry valve initially closed.

For ILOV=1 and Qo=0;

- For ILOV=1; Input downstream boundary indicator (i.e. IDN = 1, 2 or 3 )

i. $1=$ Constant pressure reservoir,

ii. $2=$ Dead end,

iii. $3=$ Trapped air at line pressure.

2. Set up and print out conditions at time zero

$\mathrm{t}=0$

3. Unsteady calculations at time increments $\Delta \mathrm{t}$

4. Internal node calculations

5. Upstream boundary condition

6. Upstream valve operation

7. Column separation at upstream valve on closure

8. Column separation at downstream valve or dead end

9. Trapped air boundary (using a 1st order approx. based on the Interface velocity) at the start of the current time step

10.Preparation For next time step and data output

11. Downstream valve

12. Dead end or closed valve boundary

\section{Case studies}

The following tests could be investigated by using the above algorithm:

Upstream boundary condition:

- Constant pressure reservoir

- Upstream valve defined by a loss of pressure at defined flow condition. Opening or closure of valve at specified time.

Pipe-line condition:

- Fluid properties defined by its density, bulk modulus and vapour pressure.

- Single pipeline of any length, diameter, wall thickness, Young's modulus and friction factor.

Downstream boundary condition:

- Valve, defined by a pressure loss at a known through flow, Opening or closing at specified time.

- Constant pressure reservoir, dead ended pipe or trapped air volume at initial line pressure as a number pipe sections. Accordingly, eleven illustrations were considered in the present study. Input data for different transient conditions are shown in Table 1.

Table 1.Input data used at different transient conditions

\begin{tabular}{|c|c|c|c|c|c|c|c|c|c|c|c|}
\hline Input & 1 & 2 & 3 & 4 & 5 & 6 & 7 & 8 & 9 & 10 & 11 \\
\hline $\mathrm{L}(\mathrm{m})$ & 15.00 & 15.00 & 15.00 & 15.00 & 15.00 & 15.00 & 15.00 & 15.00 & 15.00 & 15.00 & 15.00 \\
\hline $\mathrm{T}(\mathrm{m})$ & 0.0025 & 0.0025 & 0.0025 & 0.0025 & 0.0025 & 0.0025 & 0.0025 & 0.0025 & 0.005 & 0.005 & 0.008 \\
\hline ff & 0.008 & 0.008 & 0.008 & 0.008 & 0.008 & 0.008 & 0.008 & 0.008 & 0.008 & 0.008 & 0.008 \\
\hline $\begin{array}{l}\text { Pvap } \\
\left(\mathrm{N} / \mathrm{m}^{2}\right)\end{array}$ & & 100.00 & 100.00 & 100.00 & 100.00 & 100.00 & 100.00 & 100.00 & 100.00 & 100.00 & $\begin{array}{l}100.0 \\
0\end{array}$ \\
\hline $\begin{array}{l}\mathrm{RO} \\
\left(\mathrm{kg} / \mathrm{m}^{3}\right)\end{array}$ & & $\begin{array}{l}1000.0 \\
0\end{array}$ & $\begin{array}{l}1000.0 \\
0\end{array}$ & $\begin{array}{l}1000.0 \\
0\end{array}$ & $\begin{array}{l}1000.0 \\
0\end{array}$ & $\begin{array}{l}1000.0 \\
0\end{array}$ & $\begin{array}{l}1000.0 \\
0\end{array}$ & $\begin{array}{l}1000.0 \\
0\end{array}$ & $\begin{array}{l}1000.0 \\
0\end{array}$ & $\begin{array}{l}1000.0 \\
0\end{array}$ & $\begin{array}{l}1000 . \\
00\end{array}$ \\
\hline $\mathrm{K}\left(\mathrm{N} / \mathrm{m}^{2}\right)$ & & $2.0 \times 10^{9}$ & $2.0 \times 10^{9}$ & $2.0 \times 10^{9}$ & $2.0 \times 10^{9}$ & $2.0 \times 10^{9}$ & $2.0 \times 10^{9}$ & $2.0 \times 10^{9}$ & $2.0 \times 10^{9}$ & $2.0 \times 10^{9}$ & $\begin{array}{l}2.0 \times 1 \\
0^{9}\end{array}$ \\
\hline.$c(m / s)$ & $\begin{array}{l}1080.1 \\
2\end{array}$ & $\begin{array}{l}1080.1 \\
2\end{array}$ & $\begin{array}{l}1080.1 \\
2\end{array}$ & $\begin{array}{l}1080.1 \\
2\end{array}$ & 966.09 & 907.48 & 797.72 & 545.77 & 780.18 & 599.14 & $\begin{array}{l}720.0 \\
8\end{array}$ \\
\hline $\begin{array}{l}\text { Qvo } \\
\left(\mathrm{m}^{3} / \mathrm{s}\right)\end{array}$ & 0.0001 & 0.0001 & 0.0001 & 0.0001 & 0.0001 & 0.0001 & 0.0001 & 0.0001 & 0.0001 & 0.0001 & $\begin{array}{l}0.000 \\
1\end{array}$ \\
\hline $\begin{array}{l}\text { (t) valve } \\
\text { (sec.) }\end{array}$ & 0.002 & 0.002 & 0.002 & 0.002 & 0.002 & 0.002 & 0.002 & 0.002 & 0.002 & 0.002 & 0.002 \\
\hline VDIR & 1 & 1 & 1 & 1 & 1 & 1 & 1 & 1 & 1 & 1 & 1 \\
\hline
\end{tabular}


Surge Analysis Using Transient Pressure Theory

\begin{tabular}{|c|c|c|c|c|c|c|c|c|c|c|c|}
\hline $\begin{array}{l}\text { Tmax } \\
\text { (sec.) }\end{array}$ & 1.0 & 1.0 & 1.0 & 1.0 & 1.0 & 1.0 & 1.0 & 1.0 & 1.0 & 1.0 & 1.0 \\
\hline $\begin{array}{l}\mathrm{P}_{\text {upstream }} \\
\left(\mathrm{N} / \mathrm{m}^{2}\right)\end{array}$ & $\begin{array}{l}\begin{array}{l}5000.0 \\
0\end{array} \\
\end{array}$ & $\begin{array}{l}5000.0 \\
0\end{array}$ & $\begin{array}{l}5000.0 \\
0\end{array}$ & $\begin{array}{l}5000.0 \\
0\end{array}$ & $\begin{array}{l}5000.0 \\
0\end{array}$ & $\begin{array}{l}5000.0 \\
0\end{array}$ & $\begin{array}{l}5000.0 \\
0\end{array}$ & $\begin{array}{l}5000.0 \\
0\end{array}$ & $\begin{array}{l}5000.0 \\
0\end{array}$ & $\begin{array}{l}5000.0 \\
0\end{array}$ & $\begin{array}{l}5000 . \\
00\end{array}$ \\
\hline $\begin{array}{l}\text { Line_Pr } \\
\left(\mathrm{N} / \mathrm{m}^{2}\right)\end{array}$ & $\begin{array}{l}2000.0 \\
0\end{array}$ & $\begin{array}{l}2000.0 \\
0\end{array}$ & $\begin{array}{l}2000.0 \\
0\end{array}$ & $\begin{array}{l}2000.0 \\
0\end{array}$ & $\begin{array}{l}2000.0 \\
0\end{array}$ & $\begin{array}{l}2000.0 \\
0\end{array}$ & $\begin{array}{l}2000.0 \\
0\end{array}$ & $\begin{array}{l}2000.0 \\
0\end{array}$ & $\begin{array}{l}2000.0 \\
0\end{array}$ & $\begin{array}{l}2000.0 \\
0\end{array}$ & $\begin{array}{l}2000 . \\
00\end{array}$ \\
\hline IDN & 1 & 2 & 3 & 3 & 3 & 3 & 3 & 3 & 3 & 3 & 3 \\
\hline $\begin{array}{l}\text { Exit } \\
\text { Boundary }\end{array}$ & $\begin{array}{l}\text { Consta } \\
\text { nt } \\
\text { Pressur } \\
\text { e } \\
\text { Reserv } \\
\text { oir } \\
\text { Bounda } \\
\text { ry }\end{array}$ & $\begin{array}{l}\text { Dead } \\
\text { Ended } \\
\text { Pipe }\end{array}$ & $\begin{array}{l}\text { Trappe } \\
\text { d Air } \\
\text { Pocket }\end{array}$ & $\begin{array}{l}\text { Trappe } \\
\text { d Air } \\
\text { Pocket }\end{array}$ & $\begin{array}{l}\text { Trappe } \\
\text { d Air } \\
\text { Pocket }\end{array}$ & $\begin{array}{l}\text { Trappe } \\
\text { d Air } \\
\text { Pocket }\end{array}$ & $\begin{array}{l}\text { Trappe } \\
\text { d Air } \\
\text { Pocket }\end{array}$ & $\begin{array}{l}\text { Trappe } \\
\text { d Air } \\
\text { Pocket }\end{array}$ & $\begin{array}{l}\text { Trappe } \\
\text { d Air } \\
\text { Pocket }\end{array}$ & $\begin{array}{l}\text { Trappe } \\
\text { d Air } \\
\text { Pocket }\end{array}$ & $\begin{array}{l}\text { Trapp } \\
\text { ed Air } \\
\text { Pocket }\end{array}$ \\
\hline $\begin{array}{l}\text { Trapped } \\
\text { air } \\
\text { volume in } \\
\text { cum. }\end{array}$ & Nil & Nil & Nil & $\begin{array}{l}0.0009 \\
9\end{array}$ & $\begin{array}{l}0.0040 \\
3\end{array}$ & $\begin{array}{l}0.0078 \\
6\end{array}$ & 0.0267 & 0.513 & 0.512 & 4.021 & 4.021 \\
\hline
\end{tabular}

\section{RESULTS AND DISCUSSIONS}

From the Figure 2 for $\mathrm{N}=6, \mathrm{IDN}=1$; the wave speed was obtained as $1080.12 \mathrm{~m} / \mathrm{sec}$. The pressure rises sharply to the magnitude $4936.97 \mathrm{~N} / \mathrm{m}^{2}$ of initial stage. After damping it attains constant pressure 2439.85 $\mathrm{N} / \mathrm{m}^{2}$ onwards $0.164 \mathrm{sec}$ due to the condition of constant pressure reservoir at downstream end. Similar trend was also observed for $\mathrm{N}=8$ and $\mathrm{N}=10$.

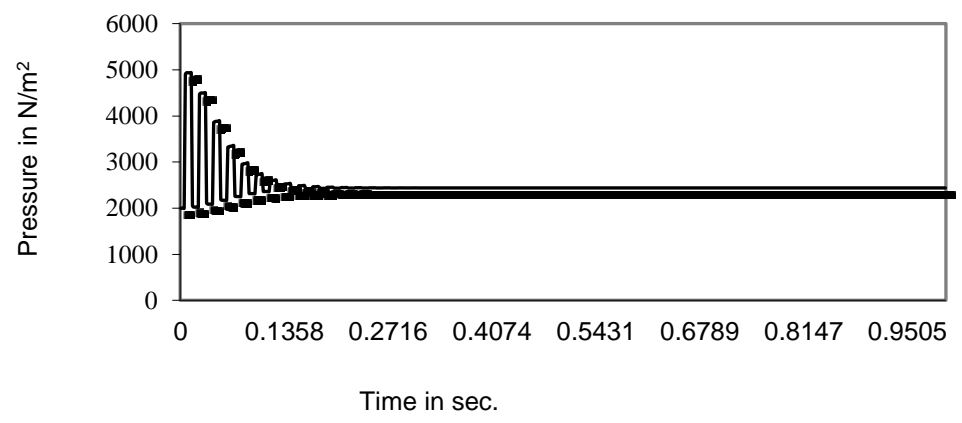

Figure 2 Pressure vs time, case 2: $\mathrm{N}=6$ and IDN=1

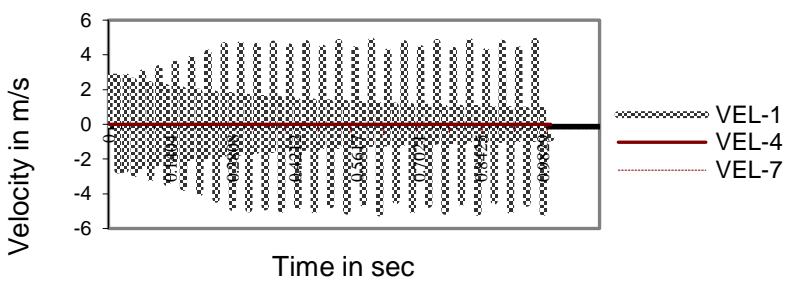

Figure 3 (a) Fluid velocity vs time, Case $2: \mathrm{N}=6 ;$ IDN $=2$ at node 1,4 , and 7

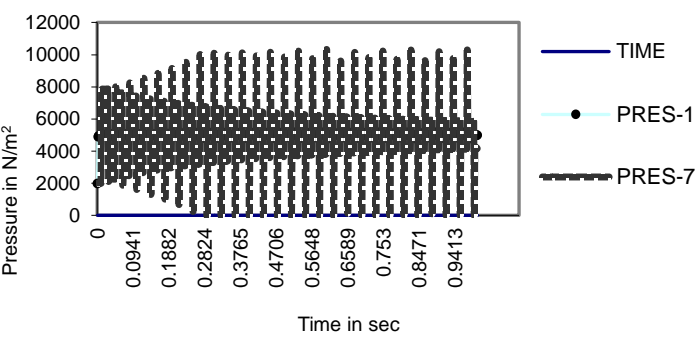

Figure 3 (b) Fluid pressure vs time Case2: $\mathrm{N}=6$; IDN=2for node 1 and 7

1. From Figure 3(a), the maximum range fluid velocity at node 1 lies between -4.821 to $4.981 \mathrm{~m} / \mathrm{s}$ during $\Delta \mathrm{t}=0.31-0.30$ i.e. $0.01 \mathrm{sec}$. Whereas at node 4 it lies between -3.024 to $3.116 \mathrm{~m} / \mathrm{s}$ during the same interval of time and the velocity at node 7 remains zero throughout. From Figure 3(b), it was observed that the variation of pressure in the range of 4987 to $5164 \mathrm{~N} / \mathrm{m}^{2}$ and at node 7 pressure rapidly increases up to $0.26 \mathrm{sec}$ and then it is fluctuating within the range of 0.1 to $9721 \mathrm{~N} / \mathrm{m}^{2}$ due to the dead ended type of exit boundary condition.

2. Figure 4 for $\mathrm{N}=6, \mathrm{IDN}=2$ and ILOV $=2$ the pressure at node 1 was constant at $5000 \mathrm{~N} / \mathrm{m}^{2}$ and at nodes 4 and 7 the pressures were found constant at $4266.94 \mathrm{~N} / \mathrm{m}^{2}$ and $3533.79 \mathrm{~N} / \mathrm{m}^{2}$ after $\mathrm{t}=0.18$ and 0.24 sec. respectively. 


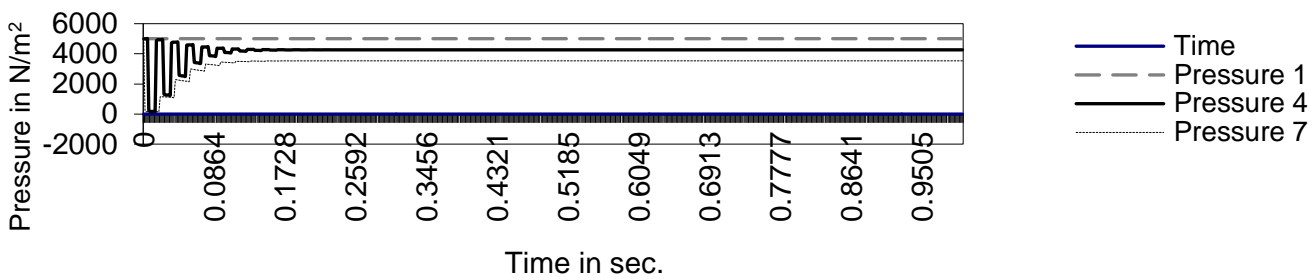

Fig 4 Fluid pressure vs time,

case 3: Fluid pressure vs time for $\mathrm{N}=6, \mathrm{IDN}=3$ and ILOV=2 (Valve at exit)

at node 1,4 and 7

Figure 5 illustrates the pressure and velocity variations expected at the interface between the trapped air and the fluid column. The trapped air pressure rises sharply over the final stages of compression and the velocity of the fluid column falls to zero and then reverses as the trapped air re-expands as a result of the transient generated by boundary as mentioned in the case of constant pressure reservoir. Fig. 5 further illustrates that the fluid velocity reaches a maximum value just prior to the rapid pressure rise associated with the compression of air pocket.
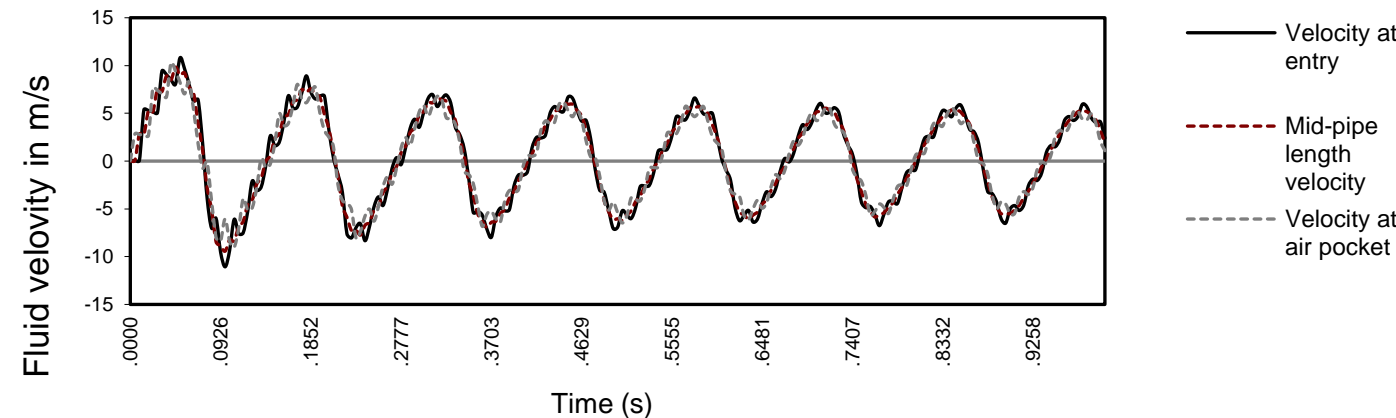

Figure 5 (a) Fluid velocity at three points
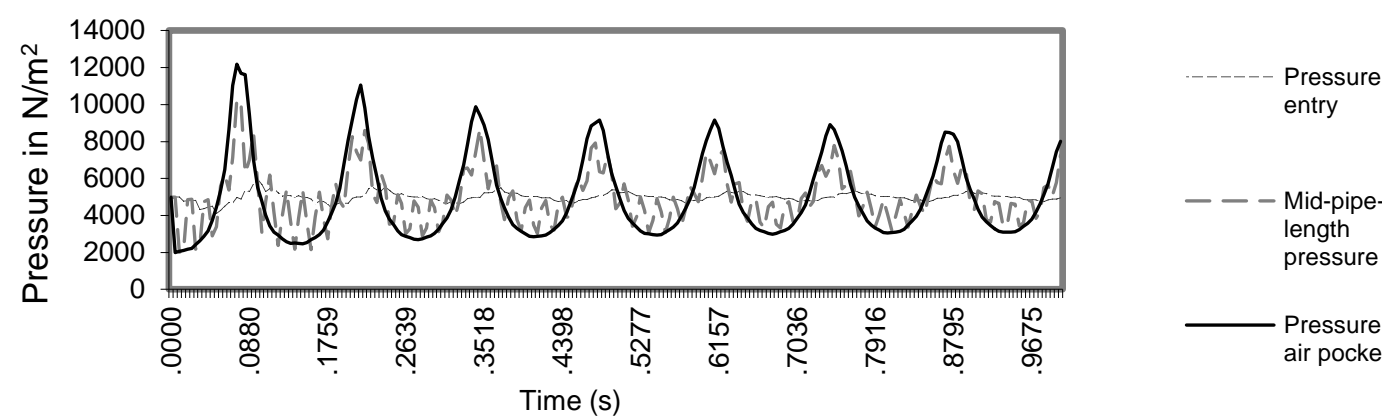

Figure 5 (b) Fluid pressures at three points

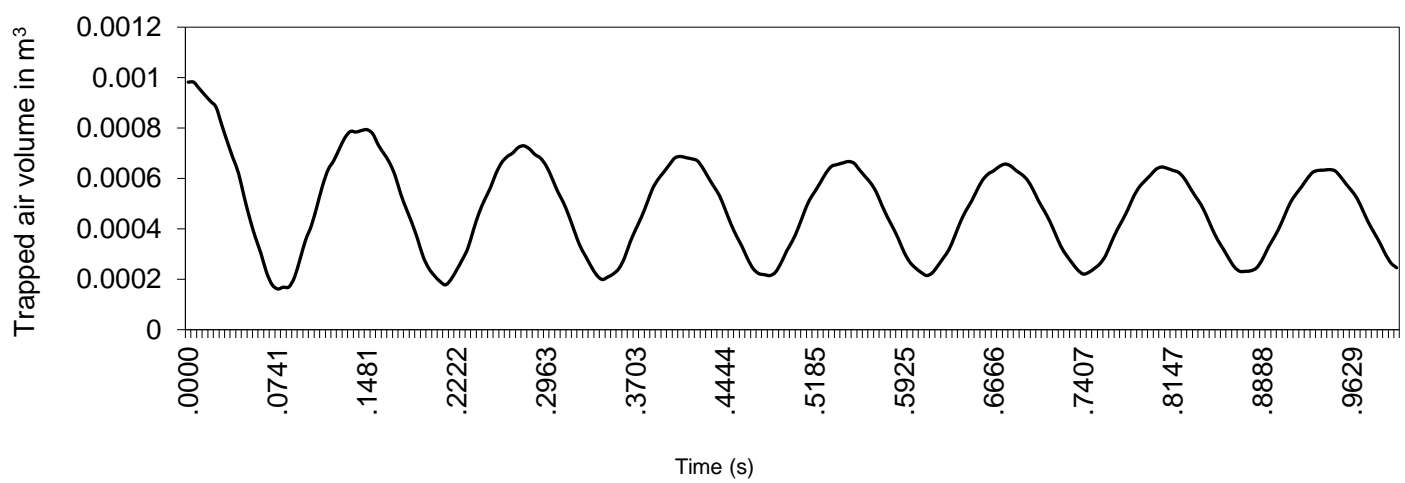

Figure 5 (c) Possible cavity formation due to trapped air 


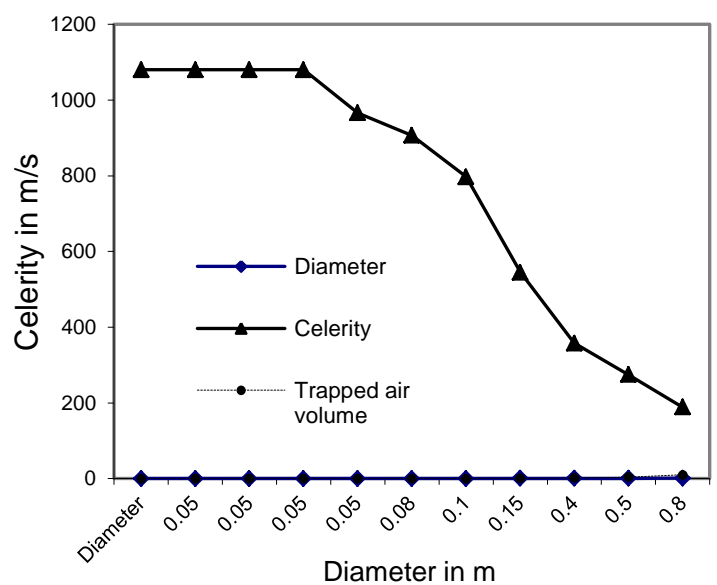

Fig. 6 (a) Relationship between pipe diameter with celerity and trapped air volume

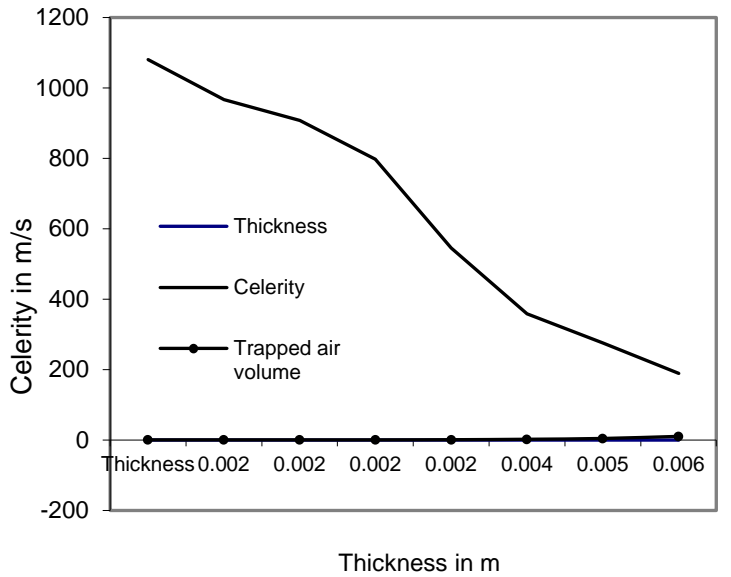

Fig. 6 (b) Relation between thickness with celerity and trapped air volume

It was also observed from the Figure 6(a) and Figure 6(b) that as the diameter of the pipe increases the velocity of the wave (or celerity) decreases with the increase in volume of the trapped air. Similarly the thickness of the pipe increases, the celerity increases; however this has no effect with the volume of the trapped air.

\section{CONCLUSION}

The study represents that a treatment of water hammer effects outlining the pressure oscillations. The study is applicable to numerical solutions to surge analysis including the transient propagation, effects of column separation and trapped air. The effects of various major parameters viz. Valve position, valve direction and downstream boundary conditions can be studied using the developed software (or algorithm) for pressure transient system in closed conduits/pipes.

\section{REFERENCES}

[1] Parmakian J. Water Hammer Analysis, (Dover Publications. Inc., New York, 1963).

[2] Fox J. A. Hydraulic Analysis of Unsteady Flow in Pipe Networks, (Macmillan Pub., London (1977)

[3] Wylie E. B. and Streeter V. L. Fluid Transients, (FEB Press, Ann Arbor, Michigan 1983).

[4] Douglas J.F., Gasiorek J. M. and Swaffield J. A. Fluid Mechanics, (Pearson Education, Inc., 2003).

[5] Schieldt H. C++: The Complete Reference, (Tata-McGraw Hill Publications. Third Edition, New Delhi 2007).

[6] Valunjkar S.S. and Shrivastava, Surge analysis: column separation and effect of trapped air using transient pressure theory4th International Conference on Mechanical Engineering, December 26-28, 2001, Dhaka, Bangladesh/pp. IV 45-51 